\title{
The Effect of Extensor Muscle Strength on Meniscus Progression in Subjects Without Radiologic Knee Osteoarthritis - Data From the Osteoarthritis Initiative
}

\author{
Mingyang Li \\ Westchina hospital『Sichuan University \\ Yong Nie \\ westchina hospital, Sichuan University \\ Kang Li \\ westchina hospital, Sichuan University \\ Yi Zeng \\ Sichuan University West China Hospital \\ Yuangang Wu \\ Sichuan University West China Hospital \\ Yuan Liu \\ Sichuan University West China Hospital \\ Limin Wu \\ Sichuan University West China Hospital \\ Bin Shen ( $\nabla$ shenbin_1971@163.com ) \\ Sichuan University West China Hospital
}

Research article

Keywords: extensor muscle strength, meniscus, knee osteoarthritis

Posted Date: March 11th, 2021

DOI: https://doi.org/10.21203/rs.3.rs-285410/v1

License: (c) (i) This work is licensed under a Creative Commons Attribution 4.0 International License. Read Full License 


\section{Abstract}

\section{Background}

High extensor strength decreased knee osteoarthritis symptomatic progression in female was well demonstrated. However, few studies detected a significant association between extensor strength and structural progression when joint space narrowing or cartilage loss were the indicators. The pathological change in meniscus could come earlier than that in cartilage and JSN, but no studies have specifically investigated the association between extensor strength and meniscus progression.

\section{Methods}

Participants in Osteoarthritis Initiative with both muscle strength and meniscus assessment, KL grade $\leq$ 1 , and $\mathrm{BMI}<30$, were enrolled. In separate-sex analysis, participants were divided into the high strength group and the low strength group referring to the median baseline maximum extensor muscle strength/weight. Overall and classified meniscus progression in MRI Osteoarthritis Knee Score was compared between the two groups, at 12 months (622 knees) and 24 months (548 knees).

\section{Results}

In females, less overall medial meniscus progression (11.1\% [17/153] VS 23.2\% [32/138], P=0.04), less medial meniscal medially extrusion (5.2\% [8/155] VS $12.5 \%$ [18/144], $P=0.04)$, and less medial meniscal anteriorly extrusion progression ( $0 \%$ [0/108] VS 5.3\% [6/113], $\mathrm{P}=0.03$ ), was presented in the high strength group over 24 months. No significant difference was detected in other comparisons (in males, or in lateral meniscus, or in 12 months).

\section{Conclusion}

High baseline extensor strength in females was associated with a decreased risk of 24- month medial meniscus progression. High extensor strength does not only correlate with less symptomatic progression of KOA, but also with lower risk of structural progression.

\section{Highlights}

1. For the first time to investigate whether different baseline extensor muscle strength affected the progression of the meniscus in MRI Osteoarthritis Knee Score (MOAKS)

2. In females, less overall medial meniscus progressio, less medial meniscal medially extrusion, and less medial meniscal anteriorly extrusion progression, was presented in the high strength group over 24 months.

3. This study proved that high extensor strength did not only correlate with less symptomatic progression of KOA, but also correlated with lower risk of structural progression. 


\section{Introduction}

Knee osteoarthritis (KOA) is a common disabling disease, with considerable individual and societal burdens[1]. Skeletal muscle structure and function were widely researched in the onset, progression, and treatment of KOA. Strengthening exercise was listed as one of the core recommended treatment in the Osteoarthritis Research Society International (OARSI) guidelines for the non-surgical management of knee osteoarthritis[2].

Extensor strengthening was the cornerstone of traditional OA exercise therapy [3], and higher extensor muscle strength decreased the symptomatic progression, particularly in females, was well demonstrated [4-7]. However, the significant association between extensor muscle strength and structural progression was rarely detected. Except that Segal et al. reported an increased risk of tibiofemoral joint space narrowing (JSN) in females with lower quadriceps strength [8], previous studies failed to found a significant association between lower knee extensor muscle strength and the tibiofemoral JSN $[6][9,10]$. In addition to JSN, researchers also investigated structural changes in cartilage, but still, no significant association between extensor muscle strength and tibiofemoral cartilage loss[11] [12] or cartilage WholeOrgan MRI Scores (WORMS) decrease [12] was detected.

KOA is systematic changes involving cartilage, subchondral bone, ligaments, synovial membrane, muscle, and menisci. JSN and cartilage change are widely used indicators of KOA structural progression, but they often emerge at relatively late stages and are affected by multiple factors, which might account for that previous studies failed to clearly illuminate the effect of extensor muscle strength on JSN and cartilage change. Therefore, evaluation of earlier structural pathological change might assist in determining the role of extensor muscle strength in KOA structural progression. Menisci play a critical protective role in the knee joint through absorbing shock, distributing load, Enhancing stability, and lubricating motion [13] [14]. Damage or extrusion of the meniscus leads to an increment in biomechanical stress on the knee joint, which results in further deterioration such as cartilage loss, subchondral bone deformation, bone marrow lesions, and synovitis. Those biological changes eventually lead to KOA[15]. Most importantly, in MRI, visible meniscal damage was presented before visible cartilage changes in many instances[16].

Therefore, this study aimed for the first time to investigate whether different baseline extensor muscle strength affected the progression of the meniscus in MRI Osteoarthritis Knee Score (MOAKS). With the earlier pathological change being investigated, a better understanding of the relationship between extensor muscle strength and KOA structural change might be achieved.

\section{Materials And Methods}

\section{Subjects}

In the Osteoarthritis Initiative (OAI) participants (https://nda.nih.gov/oai), MOAKS scores were measured at different time points according to the projects. The number of participants who were receiving 
baseline, 12 months or 24 months was larger than other time points, and therefore the periods from baseline to 12 months and from baseline to 24 months were analyzed in this study. As shown in the flowchart (figure 1) \records with insufficiency measurement or duplicate records were screened out. Participants with $\mathrm{BMI}>30$ or Kellgren-Lawrence $(\mathrm{KL})$ grade $>1$ were excluded because overweight [17] [18] or existing radiologic OA might lead to deterioration of meniscus. Basic demographics, including sex, race, side, age, height, weight, KL grade, Knee Injury And Osteoarthritis Outcome Score Quality Of Life Score (KOOSQOL), joint space narrowing (OARSI grades 0-3) medial compartment (XRJSM), joint space narrowing (OARSI grades 0-3) lateral compartment (XRJSL), were exported from the OAI database.

\section{Muscle strength measurement}

The isometric knee extensor strength $(\mathrm{N})$ was measured using the "Good Strength Chair" (Metito Oy, Jyvaskyla, Finland) at $60^{\circ}$ knee flexion $[19,20]$. Maximum extensor force was measured from the isometric strength test. In this study, extensor muscle strength was described by the maximum extensor force/weight. The high extensor strength group and the low extensor strength group were divided referring to the median extensor muscle strength/weight at the baseline.

\section{Semi-Quantitative measurements of menisci}

MOAKS was applied in this study, which described what the abnormality was and where this occurred in the menisci. MOAKS scaling could be divided into extrusion part and morphology part. Extrusion in four positions (medial meniscus medial extrusion, medial meniscus anterior extrusion, lateral meniscus lateral extrusion, lateral meniscus anterior extrusion) was graded as Grade 0:<2mm; Grade 1: 2 to $2.9 \mathrm{~mm}$, Grade 2: 3-4.9mm; Grade 3: $>5 \mathrm{~mm}$. Signal abnormality, vertical tear, horizontal and radial tear, complex tear, root rear, partial maceration, progressive partial maceration, complete maceration, cyst, and hypertrophy were assessed as presence or absence in the anterior horn, body, and posterior horn of each meniscus. Root tear was only assessed in the posterior horn. In order to conduct the longitudinal evaluation, definitions for progression of MOAKS features proposed by Runhaar et al.[21] were applied in this study (supplementary 1). The overall meniscus progression was seen as occurring when at least one classified progression was observed.

\section{Quantitative measurements of menisci}

The volume of menisci was measured based on the knee MRI scans to assess the OA progression. The analyses on these images were performed by biomediq $[22,23]$. The framework demonstrated precision and accuracy comparable to manual segmentations. The framework combined multi-atlas rigid registration with voxel classification and was trained on manual segmentations with varying configurations of bones, cartilages, and menisci. [22].

\section{Statistical analyses}

Independent t-tests (for continuous variables) and Pearson chi-squared tests (for categorical variables) were used to investigate the differences between the high extensor strength group and the low extensor 
strength group in demographics at baseline, the volume change of meniscus, and meniscus progression. Considering the distinction in muscle strength between males and females, the primary outcomes of this study in each sex were separately analyzed. Logistic regression models adjusted for baseline age, height, weight, side, $\mathrm{KL}$ grade were used to assess the relationship between extensor muscle strength and meniscal deterioration. SPSS version 25 was used for statistical analysis, and the difference was considered as significant when P-value $<0.05$.

\section{Results}

\section{From baseline to 12 months}

393 female participants were divided into the low extensor strength group and the high extensor strength group according to the median value of the extensor muscle strength/ weight. The majority of demographics between groups presented no significant difference, except for mean age, weight, and BMI (Table 1). Generally, extensor strength decreased with age, which might explain the low extensor strength group was with older mean age. Meanwhile, grouping was based on extensor muscle strength/weight, and it is comprehensible that the mean weight and BMI in the low extensor strength group was higher. Anyhow, those variables might be confounding factors and multiple variables logistics regression is necessary. 229 male participants were likewise divided into two groups. The male subject demographics between groups resemble the female's and was presented in supplementary 2 . 
Table 1

baseline demographics of female participants with baseline and 12-month meniscus measurement

Low group

\section{Subjects baseline}

Number

196

Age $($ mean $\pm S D)$

$64.41 \pm 8.61$

$68.94 \pm 8.66$

$1623.83 \pm 65.40$

$26.26 \pm 2.71$

$71.90 \pm 19.81$

$74 / 122$

$149 / 47$

$169 / 27$

94/102

Side (right /left)

Meniscus baseline

MMTMA

MMTMB

MMTMP

MMTMM

Normal 185
Signal abnormality 11

Tear or maceration 0

Normal 141

Signal abnormality 38

Tear or maceration 17

Normal 67

Signal abnormality 102

Tear or maceration 27

Grade 0:146

Grade 1: 41

Grade 2: 9

Grade 3: 0
High group

$\mathbf{P}$
197

$59.81 \pm 8.74$

$<0.05$

$64.48 \pm 8.67$

$<0.05$

$1625.16 \pm 58.31$

0.83

$24.47 \pm 2.86$

$<0.05$

$75.10 \pm 20.76$

0.14

$82 / 115$

0.43

$155 / 42$

0.53

$183 / 14$

0.03

$116 / 81$

$<0.05$

Normal 192

0.09

Signal abnormality 4

Tear or maceration 1

Normal 152

0.38

Signal abnormality 28

Tear or maceration 17

Normal 54

0.33

Signal abnormality 111

Tear or maceration 32

Grade 0:149

0.46

Grade 1: 42

Grade 2: 5

Grade 3: 1

MMTMA: medial meniscal morphology - anterior horn; MMTMB: medial meniscal morphology - body; MMTMP: medial meniscal morphology - posterior horn; MMXMM: medial meniscal extrusion medially; MMXMA: medial meniscal extrusion - anteriorly; MMRTM: medial meniscal root tear 


\begin{tabular}{|llll|}
\hline & Low group & High group & P \\
\hline MMTMA & Grade 0: 90 & Grade 0:76 & 0.79 \\
& Grade 1: 5 & Grade 1: 6 & \\
& Grade 2: 6 & Grade 2: 4 & - \\
\hline MMRTM & No 196 & No 196 & \\
& Yes 0 & Yes 0 & \\
\hline $\begin{array}{l}\text { MMTMA: medial meniscal morphology - anterior horn; MMTMB: medial meniscal morphology - body; } \\
\text { MMTMP: medial meniscal morphology - posterior horn; MMXMM: medial meniscal extrusion - } \\
\text { medially; MMXMA: medial meniscal extrusion - anteriorly; MMRTM: medial meniscal root tear }\end{array}$ \\
\hline
\end{tabular}

For both male and female participants, no significant difference in the overall meniscus progression was shown between the low extensor strength group and the high extensor strength group. (Table 3)

\section{From baseline to 24 months}

Notably, 24 months assessment were not equal to the subsequent follow-up of above patients with 12 months assessment, because 12 months assessment and 24 months assessment may from different projects of OAI with different subjects. 340 female participants were divided into two groups (Table 2). Similarly, 208 male participants were divided into two groups (supplementary 3). For both male and female, mean age, weight, and BMI between the low extensor strength group and the high extensor strength group showed significant difference, which was similar to those over 12 months. 
Table 2

baseline demographics of female participants with baseline and 24-month meniscus measurement

\begin{tabular}{|c|c|c|c|}
\hline & Low group & High group & $\mathbf{P}$ \\
\hline \multicolumn{4}{|l|}{ Subject baseline } \\
\hline Number & 170 & 170 & - \\
\hline Age $($ mean $\pm S D)$ & $63.18 \pm 8.61$ & $59.78 \pm 8.54$ & $<0.05$ \\
\hline WEIGHT $($ mean \pm SD) & $69.52 \pm 8.37$ & $64.29 \pm 8.55$ & $<0.05$ \\
\hline Height (mean \pm SD) & $1623.55 \pm 60.84$ & $1620.28 \pm 56.18$ & 0.61 \\
\hline $\mathrm{BMI}($ mean $\pm \mathrm{SD})$ & $26.33 \pm 2.37$ & $24.45 \pm 2.70$ & $<0.05$ \\
\hline KOOSQOL $($ mean \pm SD $)$ & $71.60 \pm 19.42$ & $75.73 \pm 20.14$ & 0.06 \\
\hline KL (grade 0/grade1) & $65: 105$ & $68: 102$ & 0.74 \\
\hline JSM (grade 0/grade1) & $83: 87$ & $72: 98$ & 0.23 \\
\hline Race (White /Non-white) & 148: 22 & 158: 12 & 0.07 \\
\hline Side (right /left) & 83: 87 & $97: 73$ & 0.13 \\
\hline \multicolumn{4}{|l|}{ Meniscus baseline } \\
\hline \multirow[t]{3}{*}{ MMTMA } & Normal 159 & Normal 165 & 0.09 \\
\hline & Signal abnormality 11 & Signal abnormality 4 & \\
\hline & Tear or maceration 0 & Tear or maceration 1 & \\
\hline \multirow[t]{3}{*}{ МMTMB } & Normal 122 & Normal 131 & 0.46 \\
\hline & Signal abnormality 31 & Signal abnormality 23 & \\
\hline & Tear or maceration 17 & Tear or maceration 16 & \\
\hline \multirow[t]{3}{*}{ MMTMP } & Normal 56 & Normal 47 & 0.47 \\
\hline & Signal abnormality 90 & Signal abnormality 93 & \\
\hline & Tear or maceration 24 & Tear or maceration 30 & \\
\hline \multirow[t]{4}{*}{ MMTMM } & Grade $0: 127$ & Grade 0:132 & 0.44 \\
\hline & Grade 1: 34 & Grade 1: 32 & \\
\hline & Grade 2: 9 & Grade 2: 5 & \\
\hline & Grade 3: 0 & Grade 3: 1 & \\
\hline
\end{tabular}




\begin{tabular}{|llll|}
\hline & Low group & High group & P \\
\hline MMTMA & Grade 0: 114 & Grade 0:94 & 0.96 \\
& Grade 1: 5 & Grade 1: 5 & \\
Grade 2: 5 & Grade 2: 4 & \\
\hline MMRTM & No 170 & No 170 & - \\
& Yes 0 & Yes 0 & \\
\hline
\end{tabular}

Table 3

outcomes of overall meniscus progression

\begin{tabular}{|c|c|c|c|c|c|c|}
\hline & Male & & & Female & & \\
\hline & $\begin{array}{l}\text { Low } \\
\text { group }\end{array}$ & $\begin{array}{l}\text { High } \\
\text { group }\end{array}$ & $\mathrm{P}$ & $\begin{array}{l}\text { Low } \\
\text { group }\end{array}$ & $\begin{array}{l}\text { High } \\
\text { group }\end{array}$ & $P$ \\
\hline \multicolumn{7}{|l|}{ from baseline to 12 months } \\
\hline $\begin{array}{l}\text { Medial meniscus (progression /no } \\
\text { progression) }\end{array}$ & $13 / 101$ & $7 / 108$ & 0.17 & $18 / 178$ & $14 / 183$ & 0.45 \\
\hline $\begin{array}{l}\text { Lateral meniscus (progression /no } \\
\text { progression) }\end{array}$ & $4 / 110$ & $3 / 112$ & 0.71 & $3 / 193$ & $3 / 194$ & 1.00 \\
\hline \multicolumn{7}{|l|}{ from baseline to 24 months } \\
\hline $\begin{array}{l}\text { Medial meniscus (progression /no } \\
\text { progression) }\end{array}$ & $19 / 85$ & $17 / 87$ & 0.72 & $32 / 139$ & $17 / 152$ & 0.02 \\
\hline $\begin{array}{l}\text { Lateral meniscus (progression /no } \\
\text { progression) }\end{array}$ & $8 / 96$ & $7 / 97$ & 0.79 & $9 / 161$ & $8 / 162$ & 0.80 \\
\hline
\end{tabular}

In females, less overall medial meniscus progression was presented in the high extensor strength group than that in the low extensor strength group (11.1\% [17/153] VS 23.2\% [32/138], $\mathrm{P}=0.02)$ (Table 3).

Considering that the baseline age, weight, and BMI were significantly different, multiple variables logistics regression was applied to evaluate the effect of extensor muscle strength on the meniscus progression. After adjusting the baseline age, weight, and $\mathrm{BMI}$, the adjusted $\mathrm{OR}$ for high extensor was $0.50, P=0.03$, $95 \% \mathrm{Cl}=[0.26,0.94]$.

To further investigate the association between extensor muscle strength and medial meniscus progression in female participants at 24 months. Classified medial meniscus progression was analyzed. In the analysis of overall progression, no limitation on the baseline meniscus was imposed because meniscus with no baseline abnormality in all MOAKS items was rare and no overall MOAKS evaluation had been defined before; while in the analysis of classified progression, we were able to explore MOAKS 
items one by one, excluding those with baseline pathological features in the specific item. For example, when medial meniscal medially extrusion (MMXMM) was analysed, 15 subjects with baseline grade 2 or grade 3 MMXMM was excluded to avoid bias from baseline meniscus status. For specific progressions, less MMXMM (5.2\% [8/155] VS $12.5 \%$ [18/144], $\mathrm{P}=0.04)$ and medial meniscal anteriorly extrusion (MMXMA) (0\% [0/109] VS 5.3\% [6/103], $\mathrm{P}=0.04)$ was shown in the high extensor strength group. Other types of medial meniscus progression in the high extensor strength group were also more common; however, the difference was not statistically significant. (Table 4)

Table 4

outcomes of classified medial meniscus

progression in females from baseline to 24

months, after excluding meniscus with baseline pathological features.

\begin{tabular}{|llll|}
\hline & Low group & High group & $\mathbf{P}$ \\
\hline MMTMA & $2 / 167$ & $0 / 170$ & 0.48 \\
\hline MMTMB & $9 / 144$ & $6 / 148$ & 0.42 \\
\hline MMTMP & $9 / 134$ & $7 / 136$ & 0.61 \\
\hline MMXMM & $\mathbf{1 8 / 1 4 4}$ & $\mathbf{8 / 1 5 5}$ & $\mathbf{0 . 0 4}$ \\
\hline MMXMA & $\mathbf{6 / 1 0 3}$ & $\mathbf{0 / 1 0 9}$ & $\mathbf{0 . 0 4}$ \\
\hline
\end{tabular}

\section{Change of meniscus volume}

In the FNIH project, the volume of the meniscus in 600 participants was measured. Among the 600 participants, 221 male and 322 female participants have extensor measured. The meniscus volume change between the two groups showed no significant difference. (Table 5)

Table 5

Volume change of meniscus

\begin{tabular}{|c|c|c|c|c|c|c|c|}
\hline & & Male & & & Female & & \\
\hline & & Low group & High group & $P$ & Low group & High group & $\mathrm{P}$ \\
\hline \multirow[t]{2}{*}{$\begin{array}{l}0- \\
12 \text { months }\end{array}$} & Medial & $\begin{array}{l}-62.12 \pm \\
329.10\end{array}$ & $\begin{array}{l}-105.90 \pm \\
440.51\end{array}$ & 0.41 & $\begin{array}{l}-32.49 \pm \\
198.33\end{array}$ & $\begin{array}{l}-31.80 \pm \\
192.78\end{array}$ & 0.98 \\
\hline & Lateral & $\begin{array}{l}-46.92 \pm \\
328.16\end{array}$ & $\begin{array}{l}-105.50 \pm \\
396.32\end{array}$ & 0.23 & $\begin{array}{l}-16.41 \pm \\
195.68\end{array}$ & $\begin{array}{l}-21.36 \pm \\
177.88\end{array}$ & 0.81 \\
\hline \multirow[t]{2}{*}{$\begin{array}{l}0-24 \\
\text { months }\end{array}$} & Medial & $\begin{array}{l}-333.21 \pm \\
536.16\end{array}$ & $\begin{array}{l}-318.06 \pm \\
489.85\end{array}$ & 0.82 & $\begin{array}{l}-145.73 \pm \\
339.11\end{array}$ & $\begin{array}{l}-196.16 \pm \\
308.16\end{array}$ & 0.16 \\
\hline & Lateral & $\begin{array}{l}-382.81 \pm \\
489.85\end{array}$ & $\begin{array}{l}-374.18 \pm \\
541.14\end{array}$ & 0.90 & $\begin{array}{l}-209.98 \pm \\
344.93\end{array}$ & $\begin{array}{l}-230.91 \pm \\
360.26\end{array}$ & 0.60 \\
\hline
\end{tabular}




\section{Discussion}

High extensor muscle strength has been demonstrated related to the decreased symptomatic progression of KOA. However, little evidence showed high extensor muscle strength protected subjects from KOA structural progression when JSN and cartilage loss were the indicators. Because the pathological change in meniscus often comes earlier than in cartilage, studies on meniscus seemed valued in illuminating the association between extensor muscle strength and structural change in KOA. This study's main finding is that lower risk of medial meniscus overall progression and extrusion progression was presented in the female subjects with high extensor muscle strength.

Meniscus progression, especially extrusion progression, was one of the core components of KOA structural progression. Without functioning meniscus, the contact stresses in the medial compartment increase by $40-700 \%$ [24]. Antony et al. demonstrated that extrusion was associated with KOA severity and progression[25]. Emmanuel et al. also reported that the medial meniscus extrusion distance and area were significantly greater for incident compared to non-incident knees [26]. Teichtahl et al. reported that a baseline medial meniscal extrusion was associated with accelerated cartilage loss [27]. Badlani et al. studied medial meniscus tear, degeneration, and extrusion and revealed that only medial meniscus extrusion was significantly higher in those who developed incident OA compared with the control patients[28].

Since extensor strength affected the progression of the meniscus, theoretically, lower JSN and cartilage loss were also supposed to be detected in high extensor strength, which however, was not the case in previous studies. The first explanation was the contradiction between enough follow-up and least confounding factors: researchers should follow subjects for adequate time, generally for several even to dozens of years, to observe enough detectable progression for the statistical test, while in such a long period, potential heterogeneity, like different activity level or lifestyle, hugely confounded the result. Another explanation was that the baseline meniscus status was scarcely considered in previous studies. No difference in the structural progression of cartilage or joint space between groups was detected could be accounted for the fact that another type of structural progression-meniscus progression-had occurred and not been balanced between groups. As reported previously, meniscus deterioration accounted for a substantial proportion of JSN [29] and related to cartilage loss [27].

One previous study reported meniscus results inconsistent with ours. Goldman et al. found no significant associations regarding baseline extensor muscle strength and longitudinal change in meniscus score[12]. The primary interpretation of this inconsistency was that the WORMS was applied in Goldman et al.'s study, while the MOAKS score was adopted in ours. Although both tools were semi-quantitive measurements, MOAKS was developed upon the WORMS. Especially, extrusion was not included in WORMS, which, of course, could not be measured or show any difference in Goldman et al.'s study.

The meniscus volume alteration showed no significant difference between the high and low extensor strength group, no matter for female or male, at 12 months or 24 months. The significance of meniscus volume has not been clearly demonstrated by now, especially since the meniscus volume in previous 
studies was not measured by finely enough zoning. Bloecker et al. found that compared with control knees, knees with medial compartment JSN showed greater meniscus extrusion and no significant difference in meniscus volume [30]. Therefore, the morphology and position of the meniscus seemed better indicators than the meniscus volume at present.

The sex difference existed in the relationship between meniscus progression and different extensor muscle strength. The meniscus progression in males was not significantly affected by extensor muscle strength. One potential explanation was that the female's baseline muscle strength is more likely to be lower than the absolute strength needed to protect the knee joint [31]. Sex difference in the protective effect of high knee extensor muscle strength on knee OA in females rather than in males has been observed in several individual reports [31] [32] [33].

There were several limitations to this study. First, although the 4796 participants of the OAl cohort provided this study with plenty of qualified participants, the number of each type of classified meniscal progression is still not large. In this study, the low extensor strength group had larger figures in many medial meniscus progression types, but they were without statistically significant difference. Future studies with a larger sample size might better illuminate the relationship between extensor muscle strength and each kind of meniscus deterioration. Second, although multiple logistic regression adjusting age, weight, BMI was applied to confirm the effect of extensor muscle strength, many potential confounding factors might still exist, like different activity levels of participants. Third, the protective effect of the upper half extensor muscle strength was demonstrated in this study, but no golden standard or best cut point was drawn. Studies with more participants and more elaborate grouping were required.

\section{Conclusion}

High baseline extensor muscle strength in females was associated with a decreased risk of 24- month medial meniscus progression. High extensor muscle strength is not only related to less symptomatic progression of KOA, but also related to lower risk of the structural progression.

\section{Abbreviations}

KOA: knee osteoarthritis

OARSI: Osteoarthritis Research Society International

WORMS: Whole-Organ MRI Scores

MOAKS: MRI Osteoarthritis Knee Score

OAl: Osteoarthritis Initiative

JSN: tibiofemoral joint space narrowing 
KOOSQOL: Osteoarthritis Outcome Score Quality Of Life Score

XRJSM: joint space narrowing medial compartment

XRJSL: joint space narrowing lateral compartment

$\mathrm{KL}$ : Kellgren and Lawrence

OR: odds ratios

MMTMA: medial meniscal morphology - anterior horn;

MMTMB: medial meniscal morphology - body;

MMTMP: medial meniscal morphology - posterior horn

MMXMM: medial meniscal medially extrusion

MMXMA: medial meniscal anteriorly extrusion

MMRTM: medial meniscal root tear

\section{Declarations}

\section{Ethics approval and consent to participate}

Not applicable. (All data was from public database OAl, https://nda.nih.gov/oai)

\section{Consent for publication}

Not applicable. (All data was from public database OAl, https://nda.nih.gov/oai)

\section{Availability of data and supporting materials}

All data was from public database OAl, https://nda.nih.gov/oai

\section{Competing interests}

The authors declare that they have no competing interests

\section{Funding}

This study was funded by National Natural Science Foundation of China (Program No. 81974347) and National Clinical Research Center for Geriatrics, West China Hospital, Sichuan University (NO.

Z20191008). All authors declared that the funding did not has any effect on the results of this study.

\section{Author contributions}


Study design and manuscript writing (LMY, NY, LK, SB); Data extracting (WYG, ZY) Statistical analysis (WLM, LY); Data checking (LMY, SB)

\section{Acknowledgements}

None

\section{Conflict of Interest Statement}

One the authors (SB) has received, during the study period, funding from National Natural Science Foundation of China (Program No. 81974347). One author (YZ) has received, during the study period, funding from National Clinical Research Center for Geriatrics, West China Hospital, Sichuan University (NO. Z20191008). Each other author certifies that he has no commercial associations (consultancies, stock ownership, equity interest, patent/licensing arrangements, etc.) that might pose a conflict of interest in connection with the submitted article.

\section{Ethical Committee Approval}

This study analyse data from OAl, which obtained Ethical Committee Approval before the project began

\section{References}

1. Hunter DJ, Schofield D, Callander E. The individual and socioeconomic impact of osteoarthritis. Nature Reviews Rheumatology. 2014; 10(7): 437

2. Bannuru RR, Osani MC, Vaysbrot EE, Arden NK, Bennell K, Bierma-Zeinstra SMA, Kraus VB, Lohmander LS, Abbott JH, Bhandari M, Blanco FJ, Espinosa R, Haugen IK, Lin J, Mandl LA, Moilanen E, Nakamura N, Snyder-Mackler L, Trojian T, Underwood M, McAlindon TE. OARSI guidelines for the non-surgical management of knee, hip, and polyarticular osteoarthritis. Osteoarthritis Cartilage. 2019; 27(11): 1578

3. Bennell K, Wrigley T, Hunt M, Lim B, Hinman R. Update on the role of muscle in the genesis and management of knee osteoarthritis. Rheumatic diseases clinics of North America. 2013; 39 1: 145

4. White DK, Keysor JJ, Lavalley MP, Lewis CE, Torner JC, Nevitt MC, Felson DT. Clinically important improvement in function is common in people with or at high risk of knee OA: the MOST study. The Journal of rheumatology. 2010; 37(6): 1244

5. Krishnasamy P, Hall M, Robbins SR. The role of skeletal muscle in the pathophysiology and management of knee osteoarthritis. Rheumatology (Oxford, England). 2018; 57(suppl_4): iv124

6. Culvenor AG, Ruhdorfer A, Juhl C, Eckstein F, Øiestad BE. Knee extensor strength and risk of structural, symptomatic, and functional decline in knee osteoarthritis: a systematic review and metaanalysis. Arthritis care \& research. 2017; 69(5): 649

7. Thomas E, Peat G, Mallen C, Wood L, Lacey R, Duncan R, Croft P. Predicting the course of functional limitation among older adults with knee pain: do local signs, symptoms and radiographs add 
anything to general indicators? Ann Rheum Dis. 2008; 67(10): 1390

8. Segal NA, Glass NA, Torner J, Yang M, Felson DT, Sharma L, Nevitt M, Lewis CE. Quadriceps weakness predicts risk for knee joint space narrowing in women in the MOST cohort. Osteoarthritis and cartilage. 2010; 18(6): 769

9. Miyazaki T, Uchida K, Sato M, Watanabe S, Yoshida A, Wada M, Shimada S, Kuiper JH, Baba H. Knee laxity after staircase exercise predicts radiographic disease progression in medial compartment knee osteoarthritis. Arthritis Rheum. 2012; 64(12): 3908

10. Eckstein F, Hitzl W, Duryea J, Kent Kwoh C, Wirth W. Baseline and longitudinal change in isometric muscle strength prior to radiographic progression in osteoarthritic and pre-osteoarthritic knees--data from the Osteoarthritis Initiative. Osteoarthritis and Cartilage. 2013; 21(5): 682

11. Amin S, Baker K, Niu J, Clancy M, Goggins J, Guermazi A, Grigoryan M, Hunter DJ, Felson DT. Quadriceps strength and the risk of cartilage loss and symptom progression in knee osteoarthritis. Arthritis \& Rheumatism. 2009; 60(1): 189

12. Goldman LH, Tang K, Facchetti L, Heilmeier U, Joseph GB, Nevitt MC, McCulloch CE, Souza RB, Link TM. Role of thigh muscle cross-sectional area and strength in progression of knee cartilage degeneration over 48 months-data from the Osteoarthritis Initiative. Osteoarthritis and cartilage. 2016; 24(12): 2082

13. Englund M, Guermazi A, Lohmander LS. The meniscus in knee osteoarthritis. Rheumatic Disease Clinics. 2009; 35(3): 579

14. Seedhom B, Dowson D, Wright V. Proceedings: Functions of the menisci. A preliminary study. Annals of the rheumatic diseases. 1974; 33(1): 111

15. Englund M, Roemer FW, Hayashi D, Crema MD, Guermazi A. Meniscus pathology, osteoarthritis and the treatment controversy. Nature Reviews Rheumatology. 2012; 8(7): 412

16. Englund M, Guermazi A, Roemer FW, Aliabadi P, Yang M, Lewis CE, Torner J, Nevitt MC, Sack B, Felson DT. Meniscal tear in knees without surgery and the development of radiographic osteoarthritis among middle-aged and elderly persons: the Multicenter Osteoarthritis Study. Arthritis \& Rheumatism. 2009; 60(3): 831

17. Achtnich A, Petersen W, Willinger L, Sauter A, Rasper M, Wörtler K, Imhoff AB, Diermeier T. Medial meniscus extrusion increases with age and $\mathrm{BMI}$ and is depending on different loading conditions. Knee Surgery, Sports Traumatology, Arthroscopy. 2018; 26(8): 2282

18. Hwang B-Y, Kim S-J, Lee S-W, Lee H-E, Lee C-K, Hunter DJ, Jung K-A. Risk factors for medial meniscus posterior root tear. The American journal of sports medicine. 2012; 40(7): 1606

19. Ruhdorfer A, Dannhauer T, Wirth W, Hitzl W, Kwoh CK, Guermazi A, Hunter DJ, Benichou O, Eckstein F. Thigh muscle cross-sectional areas and strength in advanced versus early painful osteoarthritis: an exploratory between-knee, within-person comparison in osteoarthritis initiative participants. Arthritis care \& research. 2013; 65(7): 1034

20. Sattler M, Dannhauer T, Hudelmaier M, Wirth W, Sanger AM, Kwoh CK, Hunter DJ, Eckstein F. Side differences of thigh muscle cross-sectional areas and maximal isometric muscle force in bilateral 
knees with the same radiographic disease stage, but unilateral frequent pain - data from the osteoarthritis initiative. Osteoarthritis and cartilage. 2012; 20(6): 532

21. Runhaar J, Schiphof D, van Meer B, Reijman M, Bierma-Zeinstra S, Oei E. How to define subregional osteoarthritis progression using semi-quantitative MRI Osteoarthritis Knee Score (MOAKS). Osteoarthritis and cartilage. 2014; 22(10): 1533

22. Dam EB, Lillholm M, Marques J, Nielsen M. Automatic segmentation of high- and low-field knee MRIs using knee image quantification with data from the osteoarthritis initiative. Journal of medical imaging (Bellingham, Wash). 2015; 2(2): 024001

23. Folkesson J, Dam EB, Olsen OF, Pettersen PC, Christiansen C. Segmenting articular cartilage automatically using a voxel classification approach. IEEE transactions on medical imaging. 2007; 26(1): 106

24. Hunter D. Degeneration of the meniscus and progression of osteoarthritis. HSS journal : the musculoskeletal journal of Hospital for Special Surgery. 2012; 8(1): 13

25. Antony B, Driban JB, Price LL, Lo GH, Ward RJ, Nevitt M, Lynch J, Eaton CB, Ding C, McAlindon TE. The relationship between meniscal pathology and osteoarthritis depends on the type of meniscal damage visible on magnetic resonance images: data from the Osteoarthritis Initiative. Osteoarthritis and cartilage. 2017; 25(1): 76

26. Emmanuel K, Quinn E, Niu J, Guermazi A, Roemer F, Wirth W, Eckstein F, Felson D. Quantitative measures of meniscus extrusion predict incident radiographic knee osteoarthritis - data from the Osteoarthritis Initiative. Osteoarthritis and Cartilage. 2016; 24(2): 262

27. Teichtahl A, Cicuttini F, Abram F, Wang Y, Pelletier J-P, Dodin P, Martel-Pelletier J. Meniscal extrusion and bone marrow lesions are associated with incident and progressive knee osteoarthritis. Osteoarthritis and Cartilage. 2017; 25(7): 1076

28. Badlani JT, Borrero C, Golla S, Harner CD, Irrgang JJ. The effects of meniscus injury on the development of knee osteoarthritis: data from the osteoarthritis initiative. The American journal of sports medicine. 2013; 41(6): 1238

29. Hunter DJ, Zhang YQ, Tu X, LaValley M, Niu JB, Amin S, Guermazi A, Genant H, Gale D, Felson DT. Change in joint space width: Hyaline articular cartilage loss or alteration in meniscus? Arthritis \& Rheumatism. 2006; 54(8): 2488

30. Bloecker K, Guermazi A, Wirth W, Benichou O, Kwoh CK, Hunter DJ, Englund M, Resch H, Eckstein F. Tibial coverage, meniscus position, size and damage in knees discordant for joint space narrowing data from the Osteoarthritis Initiative. Osteoarthritis and Cartilage. 2013; 21(3): 419

31. Thorlund JB, Felson DT, Segal NA, Nevitt MC, Niu J, Neogi T, Lewis CE, Guermazi A, Roemer F, Englund M. Effect of Knee Extensor Strength on Incident Radiographic and Symptomatic Knee Osteoarthritis in Individuals With Meniscal Pathology: Data From the Multicenter Osteoarthritis Study. Arthritis care \& research. 2016; 68(11): 1640

32. Slemenda C, Heilman DK, Brandt KD, Katz BP, Mazzuca SA, Braunstein EM, Byrd D. Reduced quadriceps strength relative to body weight: a risk factor for knee osteoarthritis in women? Arthritis 
Rheum. 1998; 41(11): 1951

33. Segal NA, Torner JC, Felson D, Niu J, Sharma L, Lewis CE, Nevitt M. Effect of thigh strength on incident radiographic and symptomatic knee osteoarthritis in a longitudinal cohort. Arthritis Rheum. 2009; 61(9): 1210

\section{Figures}

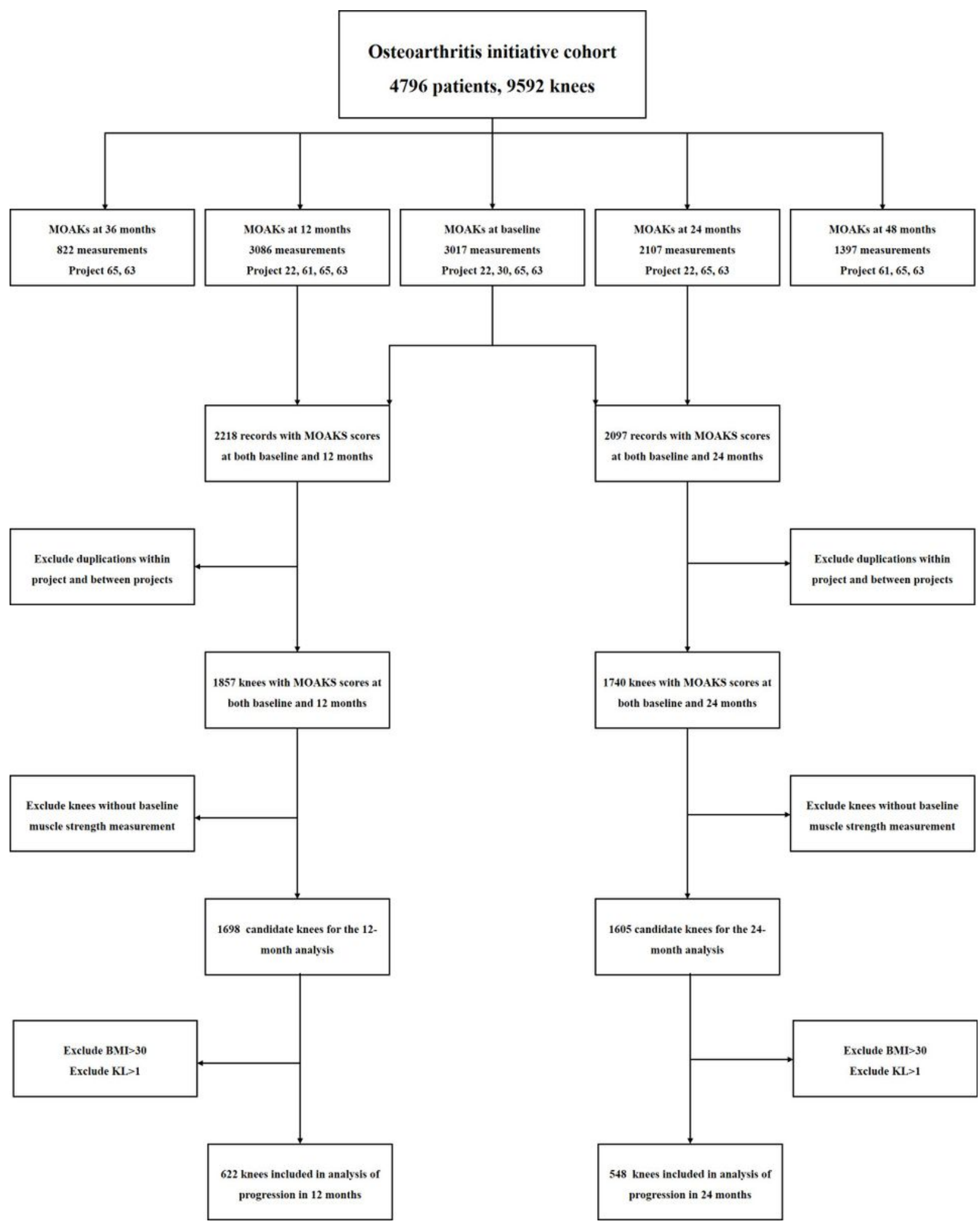




\section{Figure 1}

Flowchart of screening eligible participants

\section{Supplementary Files}

This is a list of supplementary files associated with this preprint. Click to download.

- supplementary1.docx

- supplementary2.docx

- supplementary3.docx 